\title{
Aspectos pragmáticos y discursivos de los usos eufemísticos en la comunicación pública*
}

\author{
Pragmatic and discoursive aspects \\ of euphemistic expressions in public \\ communication
}

\section{GÉRARD FERNÁNDEZ SMITH}

Grupo de investigación "Semaínein" Instituto Universitario de Investigación en Lingüística Aplicada

Área de Lingüística General

Departamento de Filología

Facultad de Filosofía y Letras

Universidad de Cádiz

Avda. Gómez Ulla, nº 1

11003 Cádiz-España

gerard.fernandez@uca.es

Resumen: El eufemismo es un fenómeno semántico relacionado con la traslación de significados que implica un sentido distinto de las unidades léxicas empleadas en un contexto determinado. Por esta razón, concebimos los usos y sustitutos eufemísticos como manifestaciones materiales del mecanismo de cohesión denominado sustitución, basado en la identidad referencial, y el eufemismo como un fenómeno pragmático y discursivo relacionado con la estrategia de la atenuación y con otras finalidades comunicativas, como la ocultación, el enmascaramiento o la difuminación de una referencia particularmente incómoda. Para su análisis, proponemos
RECIBIDO: 28 DE JUNIO DE 2016 ACEPTADO: 20 DE FEBRERO DE 2017 un enfoque desde el Análisis Crítico del Discurso que nos permita observar en las unidades léxicas y en expresiones complejas sus implicaciones semánticas y su uso como estrategia pragmática en el marco de la comunicación pública, con el fin de explorar posibilidades de aplicación en los ámbitos de la lexicografía, o más exactamente, de la lexicografía computacional, y de la política y planificación lingüísticas (libros de estilo, guías de buenas prácticas, etc.).

Palabras clave: Pragmática. Discurso. Comunicación pública. Eufemismo. Uso eufemístico.

* Este trabajo se inserta dentro de las investigaciones llevadas a cabo por el grupo "Semaínein" en el marco del proyecto "Comunicación especializada y terminografia: usos terminológicos relacionados con los contenidos y perspectivas actuales de la semántica léxica" (FFI2014-54609-P), financiado por el Ministerio de Economía y Competitividad en su convocatoria de Proyectos de I+D del Programa Estatal de Fomento de la Investigación Científica y Técnica de Excelencia de 2014. 
Abstract: Euphemism is a semantic phenomenon related to the transfer of meaning. It therefore implies a different meaning of the lexical units that are materialized in a given context. Euphemistic uses and substitutes can therefore be conceived as processes of substitution which are associated with an identical reference, and euphemism as a pragmatic and discourse phenomenon, connected to the pragmatic strategy of attenuation, as well as to other communicative goals such as occultation, the masking or blurring of a particularly unpleasant reality. Critical Discourse Analysis allows us to analyse the semantic implications of euphemism and its use as a pragmatic strategy in public communication in order to explore possible applications in the fields of lexicography, or more precisely, computational lexicography, and of language policy and planning (style books, good practice handbooks etc.).

Keywords: Pragmatics. Discourse. Public communication. Euphemism. Euphemistic use.

\section{INTRODUCCIÓN}

E

1 interés por las cuestiones que seguidamente vamos a tratar surge de la confluencia de muy diversas inquietudes científicas que nos han ocupado a lo largo de nuestra trayectoria docente e investigadora. En primer lugar, debemos situarnos en el marco de nuestra especialización, la lingüística del texto y el análisis del discurso, ámbito en el que hemos desarrollado la mayoría de nuestras investigaciones. En este sentido, la teoría del texto y el problema de la tipologización textual han supuesto las áreas en las que nos hemos detenido más frecuentemente. Basándonos en el convencimiento de que el texto es una unidad comunicativa y, por tanto, un objeto de estudio complejo, hemos defendido en numerosas ocasiones la necesidad de abordar su análisis y descripción siempre desde una perspectiva interdisciplinaria, al menos cuando se trata de comprobar la validez de ciertos principios que son lugares comunes en la teoría del texto, y no tanto de acotar la investigación hasta alguno de sus muchos aspectos parciales.

En segundo lugar, también nos hemos interesado en los últimos años por las cuestiones relativas al ámbito de la política y planificación lingüísticas, donde nos ha llamado especialmente la atención todo lo referente a la exploración de los límites impuestos por los modelos vigentes para la intervención institucional sobre las lenguas, toda vez que resulta evidente que existen hoy en día ejemplos concretos de otras formas de regular políticas sobre las lenguas que nada tienen que ver con el establecimiento de una norma estándar, ni con la defensa o la promoción de las lenguas, ni con la elevación del estatus de una determinada lengua minoritaria. Es, precisamente, en este marco en el que tratamos de describir, al menos en parte, la noción de lenguaje política- 
mente correcto y su incidencia en diversos ámbitos de comunicación y, consecuentemente, en los diferentes productos o géneros discursivos en que estos se materializan, instancia esta de lenguaje en la que el proceso del eufemismo se revela como uno de sus más importantes y llamativos recursos.

Finalmente, y ahora situados en una perspectiva más general, conviene recordar que los sistemas de comunicación lingüísticos y no lingüísticos se rigen, según Hockett (553), por una serie de propiedades (14, 15 o 16, según sus distintas versiones), siendo los lingüísticos los únicos que las cumplen todas. Entre ellas, y esto es clave para la cuestión que vamos a tratar, está la prevaricación, que se define como la propiedad de los sistemas lingüísticos que les permite referirse a lo que no existe o a lo que no es cierto (v. gr., 'mentir') y que para López García (22-24) es inherente a las lenguas, junto con la reflexividad (por la cual los elementos del sistema pueden referirse a sí mismos) y la dualidad (la propiedad de esos elementos de ser símbolos que combinan una expresión material y un contenido). Más aún, en nuestra opinión, también la propiedad del desplazamiento, que se define como la posibilidad que tienen las lenguas de permitir a sus usuarios referirse a aquello que no está presente en el contexto de la comunicación, tanto física como cronológicamente, es otra forma de prevaricación. Así pues, las lenguas son, como consecuencia de esto, instrumentos para la mentira, para el engaño, para la ficción, y uno de los fenómenos en los que se sustancia esta potencialidad es el recurso al uso eufemístico, manifestación discursiva del proceso eufemístico (Casas Gómez 2012c), entre otras formas de utilización, no solo de variantes léxicas, sino de construcciones más complejas que constituyen diferentes formas del rodeo, la perífrasis y el circunloquio, largamente conocidas en la historia de las ideas lingüísticas.

Pues bien, a partir de estas premisas, pretendemos abordar aquí una aproximación al análisis pragmático y textual de algunos ejemplos concretos extraídos de diversas fuentes de la comunicación pública, dado que este es un marco favorable para la transmisión de las representaciones colectivas que los diferentes grupos sociales tienen sobre determinados estados de cosas. Dicho de otro modo, la comunicación pública es el resultado de la transmisión de ideas (e ideologías) sobre la realidad, siempre en relación con sistemas de creencias y con saberes culturales e históricos acerca de aspectos concretos de las diferentes esferas sociales de la actividad humana. Como tal realización lingüística en contexto, dicha transmisión se produce mediante textos, o discursos si se prefiere, en los que las unidades léxicas soportan la significación global de lo 
que se quiere decir, esto es, el sentido del texto, y, a la vez, sirven como índices de la referencia a la realidad extralingüística que se pretende representar.

\section{EL LUGAR DEL LÉXICO EN EL TEXTO}

El léxico de una lengua es el subsistema fundamental para llevar a cabo actos de comunicación, pues es el elemento más importante para la constitución de su unidad mínima, el texto. Como se sabe, este presenta como fenómenos inherentes la cohesión y la coherencia, que se verifican mediante una serie de mecanismos cuya finalidad principal es la de asegurar el mantenimiento del referente y la continuidad de sentido en un texto. Precisamente, en relación con el papel que desempeña el léxico de una lengua en la conformación del entramado textual, existe una serie de procedimientos directamente relacionados con él que apuntamos ahora de manera sucinta. Algunos son de tipo formal y gramatical, pues tienen más que ver con la categoría de palabra implicada en cada caso, como son la repetición, la sustitución, ya sea mediante el uso de proformas, ya sea mediante la sustitución por cero o elipsis (ver Bernárdez), además de otras denominaciones similares a estas como las de paráfrasis, recurrencia, etc. (Beaugrande/Dressler). Otros, en cambio, dependen de la red de significaciones que se establece a partir de la concurrencia de las diferentes unidades léxicas que conforman un texto, como son la cohesión léxica, mediante colocaciones y repeticiones (Halliday/Hasan), o las denominadas relaciones semánticas entre lexemas basadas en el conocimiento del mundo (Bernárdez), que realmente responden a asociaciones cognitivas y culturales que los usuarios de las lenguas actualizan a la hora de interpretar los mensajes lingüísticos. Puesto que los límites entre la cohesión y la coherencia textuales no son tajantes, hay implicaciones pragmáticas en estos fenómenos. Incluso en el marco de la progresión temática, existen otras relaciones o asociaciones, inferencias semánticas o implicaciones, según Daneš, como por ejemplo restaurant - lunch o summer-vacation, que dan cuenta de este tipo de coocurrencias (distribuciones, si se prefiere), que se verifican por el criterio de frecuencia y que van más allá de ser solidaridades sintagmáticas (como las define Coseriu 1977), entre las unidades léxicas de un texto.

Como corolario de este planteamiento metodológico, con el que se persigue al fin y al cabo encontrar regularidades y sistematicidad dentro de unos modelos que hemos identificado siempre como patrones socioculturales, indefectiblemente llegamos al problema de la tipologización como base teórica 
de la existencia de invariantes textuales que subyacen a todo proceso discursivo efectivamente producido en cualquiera de las múltiples formas genéricas que los denominados tipos de lenguaje adoptan y que son aceptados socialmente como adecuados para el contexto en que se producen. En síntesis, el texto es una unidad comunicativa, dotada de cohesión y coherencia, que sirve de vehículo para las intenciones comunicativas expresadas como secuencias de actos de habla. Estas constituyen un número reducido de tipos invariantes de texto que adoptan, empero, diversas y numerosas formas pertenecientes a amplios conjuntos de géneros discursivos que, en virtud de la adecuación, contribuyen a que un texto determinado sea percibido, aceptado, como apropiado para el contexto en el que se emplea.

Así pues, el papel que desempeñan las unidades léxicas, dentro de la red de relaciones y correferencias que se establece jerárquicamente entre ellas (más allá de las relaciones léxicas definidas en Casas Gómez 1999), en el proceso de interpretación del sentido de un texto sitúa a la semántica léxica en la intersección de disciplinas como la pragmática, la lingüística del texto y el análisis del discurso y la retórica y la estilística. Gráficamente:

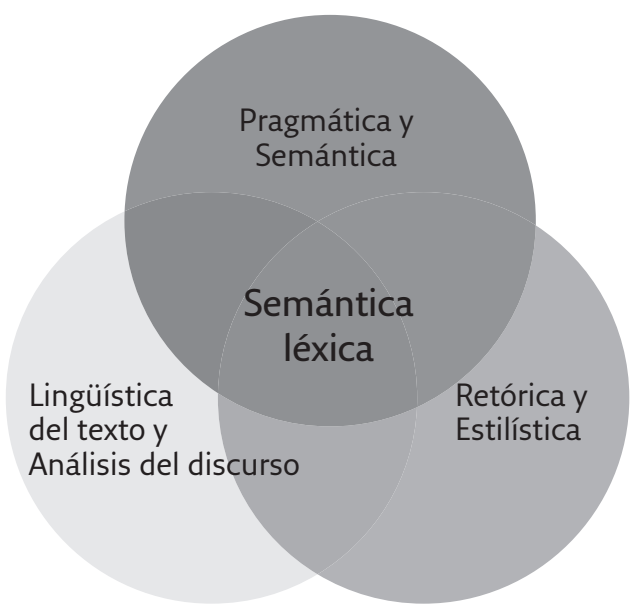

Figura 1

Por supuesto, el esquema que proponemos no agota las posibilidades de intersección, tal como lo exponen en su introducción los editores de este mismo volumen, de la semántica léxica con otras disciplinas, como pueden ser la 
sociolingüística, en parte subsumida dentro de, o mejor, relacionada con, la retórica, la estilística y la lingüística del texto mediante los conceptos de "estilo" o "registro", o la terminología, con la que establece todo tipo de trasvases cuando se añade a las unidades léxicas determinadas marcas semánticas de uso que suponen una forma de especialización de sus contenidos dentro de un determinado contexto comunicativo. Se trata, simplemente, de destacar la importancia que tiene el léxico en la configuración de los procesos comunicativos, particularmente desde el punto de vista de la lingüística del texto y el análisis del discurso, disciplinas con las que la retórica y la pragmática comparten todo tipo de técnicas y herramientas relacionadas, respectivamente, con las formas de composición de los discursos y con las estrategias comunicativas empleadas por sus productores y receptores.

Todo ello justifica, ya lo hemos dicho en otras ocasiones (Fernández Smith 2009 y 2013), la existencia en la lingüística textual y discursiva de un fenómeno inherente al texto, junto con la cobesión y la coherencia, como es el de la adecuación, que, además, puede constatarse de manera muy evidente en relación con las cuestiones que aquí tratamos. Más aún, si empezamos a considerar ahora el aspecto concreto en el que vamos a centrar nuestra discusión, el eufemismo y los usos eufemísticos, Crespo Fernández, en su estudio monográfico, defiende la existencia de relaciones entre estos fenómenos (y sus complementarios, el disfemismo y los usos disfemisticos) y las siguientes disciplinas: semántica, semiología y semiótica, psicología y psicolingüística, estilística, análisis del discurso, pragmática, sociología y sociolingüística, etnolingüística, etnografía de la comunicación, etnometodología y antropología lingüística. Es innegable la multiplicidad de puntos de vista desde los que se puede abordar el análisis de estos fenómenos, y es notable el esfuerzo analítico llevado a cabo por el autor en este sentido. Con todo, muchas de estas conexiones se desprenden de las superposiciones que las propias disciplinas implican ya de por sí, al margen de que la investigación se centre o no en los fenómenos eufemísticos y/o disfemísticos. Sin entrar en detalles acerca de cuestiones epistemológicas que, nos parece, son muy evidentes, sí que podemos, de acuerdo con esto, justificar el carácter interdisciplinar al que nos hemos referido inicialmente y, por tanto, nuestra aproximación pragmática y discursiva, desde una visión más amplia de la semántica léxica, al eufemismo y los usos eufemísticos. 


\section{CONCEPTO DE “EUFEMISMO” Y “USO EUFEMÍSTICO”}

Como se sabe el eufemismo es un fenómeno semántico que tiene que ver con la traslación de significados (Chamizo Domínguez/Sánchez Benedito 1994 y 2000). Ahora bien, dado que el eufemismo implica un sentido distinto de las unidades léxicas efectivamente empleadas en un contexto determinado, es, en nuestra opinión, un fenómeno discursivo y pragmático, tal como sostienen, entre otros, especialistas como Crespo Fernández y Casas Gómez (1986, 2009, 2012b, 2012c), quienes detallan y actualizan las diferentes concepciones, tanto lingüísticas como extralingüísticas, de este proceso. Por esta razón, concebimos el eufemismo, o mejor, los sustitutos y usos eufemísticos (ver Casas Gómez 2012c, 63-66), así como los procedimientos relacionados con este, cuando realmente se emplea un sustituto, como manifestaciones materiales del mecanismo de cohesión denominado sustitución, basado en la identidad referencial (Bernárdez), por lo que apunta directamente a la referencia como designación real en el hablar (ver Casas Gómez 2002, sobre los niveles del significar), además de que desempeña otras funciones estilísticas relacionadas con la sinonimia textual. En síntesis, el eufemismo representa, a menudo mediante la sustitución léxica, un proceso de traslación de un significado, generalmente para ocultar una realidad considerada tabú (Crespo Fernández 43-45). En este sentido, resulta esclarecedora la definición de Casas Gómez (2012c, 68-69), para quien el eufemismo y el disfemismo se deben definir como un "proceso cognitivo de conceptualización de una realidad interdicta" que se manifiesta discursivamente de muy diversas maneras, siendo la sustitución léxica solo una de sus muchas posibilidades. Dicho proceso habilita al productor del discurso para "la creación intencional de todo tipo de expresiones verbales y no verbales o actos de habla, que, en un cierto "contexto" y en una concreta situación pragmática, encubren, atenúan o realzan expresivamente, o, por el contrario, motivan o refuerzan evocativamente un determinado concepto o realidad interdicta".

Parece un hecho cierto que en la actualidad se ha generalizado una concepción de los usos y sustitutos eufemísticos como manifestaciones de una "interdicción conceptual" (Casas Gómez 2012a), ya que presentan funciones sociales y psicológicas (Chamizo Domínguez; Casas Gómez 2012a, 2012b) y motivaciones de tipo político-económico y social (Lechado García). Por tanto, el proceso eufemístico trasciende la semántica léxica y no se limita solo a un mero mecanismo de sustitución léxica, toda vez que se revela como un 
índice léxico de determinadas estrategias pragmáticas y textuales. Puede constatarse esta afirmación, por ejemplo, en un repertorio terminológico como el de Alcaraz Varó/Martínez Linares (220), pues en la definición que proporcionan estos autores, se señala que, desde un punto de vista pragmático relacionado con las máximas conversacionales de Grice, abunda particularmente en el lenguaje de los políticos “un 'eufemismo' (“expediente de regulación de empleo" o "regulación de empleo" por despido, "fusilamientos limpios", etc.) que debe considerarse especial por fallar, en la mayoría de los casos, la aludida máxima de sinceridad". De manera similar, también el diccionario terminológico de Lewandowski (128) sugiere esto mismo, aunque de forma más velada y sucinta.

En efecto, desde el punto de partida que acabamos de presentar, trataremos el eufemismo en un marco teórico definido por la pragmática, esto es, como un fenómeno pragmático y discursivo. Así, el eufemismo está directamente relacionado con la estrategia pragmática de la atenuación (Casas Gómez 2012a, 68-70). Aun así, si consideramos atenuación e intensificación como polos de una escala (Márquez Guerrero), el eufemismo, que en ocasiones presenta límites difusos con el disfemismo (Chamizo Domínguez 45), puede tener repercusiones en la estrategia de la intensificación, como demuestra, de forma contundente, Casas Gómez (2012a, 70-76). En general, el modelo teórico que subyace a la aproximación pragmática a la atenuación es el de la denominada cortesía verbal, si bien han sido identificados otros fines para los que puede emplearse esta misma estrategia, de tal manera que esta contribuye a la configuración de una auténtica retórica de la conversación (Briz 143) o, más expresivamente, retórica de la cotidianeidad (Mortara Garavelli 359). ${ }^{1}$ Finalmente, en lo que se refiere al enfoque pragmático de estas estrategias, nos parece muy adecuado describir dichos procesos como formas de violación antagónica de las máximas conversacionales (recuérdese la referencia a Grice en la definición del diccionario de Alcaraz Varó/Martínez Linares), tal como las presenta Escavy Zamora en su estudio sobre la letra pequeña en todo tipo de contratos, en instancias de la comunicación médico-paciente y en los prospectos de los

1. Por citar solo algunas fuentes, además de trabajos de referencia sobre atenuación e intensificación (Albelda Marco 2007; 2010), se han publicado investigaciones sobre los aspectos gramaticales, aplicados al español, de sus funciones interactivas (Meyer-Hermann) y sobre su relación con la argumentación en el discurso político (Márquez Guerrero) y en el discurso periodístico (De la Fuente García), que son, obviamente, ámbitos de indudable interés para nuestros propósitos, como instancias que son de la comunicación pública, pero que exceden los límites que aquí nos hemos marcado. 
medicamentos. Así por ejemplo, en el caso de los prospectos, el empleo abusivo de términos técnicos (antipirético, posología), de cultismos y otras variaciones de registro (ingesta, desleído), de siglas ( $S A S, L A B)$ y, en suma, de expresiones indescifrables, impide a los destinatarios entender lo que se les dice, en contra de lo que cabría esperar si se respeta el Principio de Cooperación de Grice (ver estos y otros ejemplos en Escavy Zamora 62-65).

Llegados a este punto, debemos prestar especial atención a esos otros casos en los que la intención comunicativa es artera porque se pretende deformar la realidad deformando el lenguaje. Así, por ejemplo, además de la referencia a esos "eufemismos especiales" en la entrada terminológica del diccionario de Alcaraz Varó/Martínez Linares que mencionamos más arriba, Crespo Fernández (45) señala, al respecto, que existe una finalidad eufemística, perniciosa, según indica, con la que se persigue "enmascarar la verdad ocultando aquellos aspectos menos convenientes para el emisor y engañando, con ello, al receptor". Para Escavy Zamora (59) en determinados ámbitos de comunicación "los eufemismos son utilizados de manera torticera, por lo que dejarían de ser auténticos eufemismos, para ser mentiras intencionadas". Si bien está muy clara la relación entre este tipo de usos intencionados de los fenómenos eufemísticos (y disfemísticos), de las perífrasis desorientadoras y de los circunloquios innecesarios con la noción de lenguaje políticamente correcto, hasta el punto de que, como afirma Casado Velarde $(2014,67)$, "politically correct language is deeply rooted in euphemism", conviene igualmente preguntarse, en este sentido, si no nos hallamos, complementariamente, ante un proceso lingüístico encaminado a la gestión de realidades que se consideran, al menos en el contexto histórico actual (ver, más abajo, los principios del Análisis Crítico del Discurso) como nuevos tabúes. Aun a riesgo de aparecer excesivamente simplistas, agrupamos aquí algunos ejemplos ${ }^{2}$ traídos a colación por su utilización en diferentes ámbitos de la comunicación pública, pero que la mirada experta rápidamente identificará con precisión por su naturaleza y funciones. En cualquier caso, todos ellos cumplen la finalidad de encubrir una realidad que es inconveniente para el emisor, y también para el receptor, si es el caso que comparte los mismos esquemas de valores y visión del mundo, aunque, es bien cierto, unos engañan más que otros:

2. Pueden hallarse numerosos ejemplos de los usos eufemísticos en la comunicación pública en Casado Velarde (2011), en las esferas de la bioética y la medicina, y en la denominada ideología de género, aún más en Casas Gómez (2009, 2012a, 2012b), especialmente sobre el desempeño de profesiones, y también en Escavy Zamora. 
- Ámbitos político y jurídico: "interrupción voluntaria del embarazo", por aborto

- Ámbito político: "conducción temporal de agua", por trasvase

- Ámbito administrativo: "auxiliar de vuelo", por azafata

- Ámbitos político y administrativo: "desempleo", por paro; "demandante de empleo", por parado

- Ámbitos político y económico: "desaceleración económica”, “crecimiento negativo", por crisis

- Ámbito publicitario: "esos días”, por periodo [menstruación]; "alivia el picor intimo", por vaginal.

Obsérvese el hecho de que, desde una perspectiva pragmático discursiva como la que aquí adoptamos, la comunicación es siempre una negociación (Beaugrande/Dressler), de manera que los usos eufemísticos, como también otras estrategias discursivas y argumentativas de las que dispone el hablante, no tienen por qué responder a un mismo punto de vista sobre las cosas, sobre la realidad extralingüística, común para hablante y oyente, sino que en no pocas ocasiones el mecanismo o la estrategia se emplea en el marco de la tensión argumentativa producto de la negociación con la finalidad de deformar esa realidad, de presentar un determinado estado de cosas, y persuadir al oyente de que las cosas son verdaderamente tal como las ha presentado el hablante.

\section{UNA NOTA METODOLÓGICA: ¿QUÉ ENTENDEMOS POR COMUNICACIÓN PÚBLICA? ¿CÓMO SE PUEDE ABORDAR SU ANÁLISIS?}

La comunicación pública es, esencialmente, aquella cuyos mensajes son producidos por un colectivo, o bien por un emisor concreto que lo representa. ${ }^{4} \mathrm{Se}$ trata de una comunicación institucional que se dirige a un receptor también colectivo, especialmente al público general, aunque puede estar dirigida a la vez a un sector de ese público, ya sea porque se trata de correligionarios, ya sea

3. De hecho, la unidad léxica íntimo/-a se emplea muy frecuentemente para ocultar la realidad del cuerpo humano en el lenguaje publicitario relacionado con los productos sanitarios y/o cosméticos para mujeres, donde coocurre junto a lexemas como higiene, cuidado, alivio, etc.

4. Aunque no abordaremos esta cuestión, porque excede nuestros propósitos, no podemos negar el interés y la importancia que puede tener, en relación con el carácter colectivo de la emisión en el marco de la comunicación pública, la polifonía textual. Puede verse, al respecto, el análisis que lleva a cabo Casado Velarde (2008) sobre esta cuestión en el discurso periodístico actual. 
porque están, de alguna manera, ya iniciados (ver, por ejemplo, Cassany para cuestiones generales relativas a la producción de este tipo de comunicación). La comunicación pública se manifiesta mediante los denominados tipos de lenguaje, esto es, en los discursos político, periodístico, jurídico-administrativo, económico, etc. Resulta en este sentido especialmente importante la comunicación periodística, ya que esta es, en muchas ocasiones, el medio de canalización y transmisión de este tipo de mensajes procedentes de otros sectores sociales y profesionales. Obviamente, resulta incontestable la obligación que se impone al lingüista de tener en cuenta numerosos factores de carácter extralingüístico a la hora de enfrentarse al análisis de dichos mensajes. Particularmente, en el caso que nos ocupa, se hace necesaria una verdadera bermenéutica que nos ayude a deslindar el verdadero sentido de los textos reales en el contexto en que se producen.

Así pues, para el análisis de estos aspectos pragmáticos y discursivos de los usos eufemísticos en el marco de las producciones de origen institucional o colectivo, adoptaremos los principios del denominado Análisis Crítico del Discurso (Van Dijk 2003; De la Fuente García; Laborda Gil), dado que la interpretación de los referentes depende de una visión global y contextualizada que permita discernir las verdaderas intenciones comunicativas y las ideologías y cogniciones sociales subyacentes, en relación con los denominados por Van Dijk (1993) discursos de las élites. ${ }^{5}$ No podemos abordar aquí en toda su extensión un planteamiento más detallado de los desarrollos de la investigación en este campo, por lo que nos limitaremos a presentar, siguiendo a Laborda Gil (43), sus principios generales, que pueden observarse en los trabajos fundamentales de Norman Fairclough y Ruth Wodak:

1. El análisis crítico del discurso trata de problemas sociales.

2. Las relaciones de poder son discursivas.

3. El discurso constituye la sociedad y la cultura.

4. El discurso realiza una tarea ideológica.

5. El discurso es histórico.

6. La relación entre texto y sociedad es mediata.

7. El análisis crítico del discurso es interpretativo y explicativo.

8. El discurso es una forma de acción social.

5. Ver Fuentes González, quien lleva a cabo una aplicación de este marco teórico y metodológico en su análisis de los discursos y de la política lingüística desarrollada durante el Franquismo español, en relación con determinados gentilicios y terminología acuñados en esa época. 
Serán, principalmente, los puntos 4, 6, 7 y 8 los que vamos a ver más claramente reflejados en nuestra discusión, y esto es así porque pretendemos demostrar lo siguiente:

a) que los usos eufemísticos y otras formas de ocultamiento del sentido y/o el referente de los signos lingüísticos son herramientas de manipulación del lenguaje en el marco de un determinado sistema de creencias o punto de vista de la realidad, lo que supone una tarea ideológica (principio 4);

b) que existen medios de transmisión de los mensajes ideológicos dirigidos a los receptores, que secundan, avalan o difunden estos usos al servicio de ese sistema de valores, de ahí también nuestro interés por la comunicación pública (principio 6);

c) que, más allá del análisis formal de las relaciones de cohesión y coherencia textuales que, como lingüistas, podemos llevar a cabo, existe la necesidad de identificar las estrategias comunicativas empleadas en determinados contextos de comunicación, con el fin de desentrañar el verdadero sentido de los elementos léxicos concretos (principio 7), y d) que, por definición, una lingüística del texto o análisis del discurso integral (ver Loureda Lamas 2010 y 2014) debe tener en cuenta las implicaciones reales de los discursos, en tanto que asume principios fundamentales de la pragmática (principio 8).

Así pues, en esta investigación proponemos un enfoque pragmático y discursivo que nos permita observar, más allá de las implicaciones semánticas del fenómeno y de su uso como estrategia pragmática de atenuación, otras finalidades comunicativas para las que este es útil, lo que, creemos, se verifica con no poca frecuencia en los mensajes que se producen en el marco más general de los patrones socioculturales que rigen los discursos denominados periodístico, político, administrativo o publicitario, por citar algunos de los más conocidos. Para ello, si bien centramos nuestro interés en las unidades léxicas, habrán de tenerse en cuenta en este análisis también las expresiones complejas, fundamentalmente porque el fenómeno del eufemismo está relacionado, ya desde la retórica, con el circunloquio, la perifrasis eufemistica, la litote y otros recursos más complejos (Mortara Garavelli 1988). Se trata de tropos impropios, construidos por desplazamiento de los límites de los significados que mantienen una cierta relación y a menudo se presentan como tropos compuestos: me- 
táfora, metonimia, litote. Lo interesante de todo esto es que, como indica la autora, además de sus propiedades estilísticas, este tipo de recursos son formas de creatividad lingüística. De hecho, "una perífrasis no se aprecia como tal cuando no coexiste con una denominación alternativa [...] en la memoria de los receptores" (Mortara Garavelli 197-98).

Con idea de explotar las posibilidades de nuestro análisis y porque abordamos un enfoque desde el Análisis crítico del discurso, describiremos los usos eufemisticos en una serie de ejemplos procedentes de un conjunto de textos ${ }^{6}$ que se caracterizan por ser de comunicación pública, puesto que, o bien son de producción colectiva, o bien, siendo producciones individuales, se emplean en ámbitos de comunicación pública en los que se sigue una pauta ideológica o preestablecida, como es, por ejemplo, la línea editorial de un medio de comunicación, o la consigna en la comunicación política. Empleamos esta denominación con idea de abarcar, no solo lo que habitualmente se entiende como texto periodístico, o texto político, o publicitario, sino también otras instancias discursivas procedentes de diferentes tipos de instituciones y organizaciones y que producen sus respectivos gabinetes de prensa o de comunicación. Desde este punto de vista tratamos de explorar el fenómeno, no solo en relación con el proceso del enfemismo, por el que un sustituto se emplea en lugar de otro elemento léxico interdicto, lo que implica un uso eufemístico, sino con el hecho de que tal procedimiento sirve al emisor para ocultar, enmascarar o difuminar una referencia que le es particularmente incómoda (Crespo Fernández 45; Escavy Zamora 58-59), sin que por ello nos encontremos ante una interdicción lingüística motivada por la presencia de un tabú. En todo caso se trata más bien de una interdicción conceptual (Casas Gómez 2012b) que se opera sobre “tabúes”, esto es, realidades incómodas, muy concretos en contextos determinados, de ahí su carácter pragmático-discursivo.

Puesto que en el eufemismo (y, por tanto, en la estrategia pragmática de la atenuación) pueden reconocerse fácilmente funciones sociales y psicológicas (Chamizo Domínguez; Crespo Fernández; Casas Gómez 2012a), es perfec-

6. Se trata, propiamente, de un conjunto de textos y no de un corpus de datos lingüísticos, puesto que, más allá de una clasificación según los ámbitos de comunicación especializada de los que los hemos extraído (textos periodísticos, técnico-científicos, publicitarios, jurídico-administrativos), estos textos no han sido sometidos aún a catalogación ni indexación mediante etiquetas. Representan un conjunto de aproximadamente 500 textos que los alumnos colaboradores del área de Lingüística General de la Universidad de Cádiz, a los que aprovechamos este foro para manifestar nuestro más sincero agradecimiento, han ido recopilando, como parte de su trabajo de colaboración, durante los últimos años. 
tamente entendible la necesidad de adoptar los principios metodológicos del Análisis crítico del discurso, que proporciona las herramientas hermenéuticas que necesitamos para identificar los referentes reales de las expresiones consideradas sobre la ideología (ver Van Dijk 1980 y De la Fuente García, sobre el discurso periodístico informativo, y también Van Dijk 2003). En este sentido, nos interesan, fundamentalmente, las que Lechado García (15-16) denomina motivaciones "de tipo político-económico", "sociales", especialmente cuando son generadas por los organismos o instituciones oficiales o las corporaciones, y por ello también aquellas motivaciones derivadas de la "necesidad de prestigio profesional". Puede verse, en este sentido, el comentario de Casas Gómez (2012a, 72) sobre los denominados eufemismos de megalomanía, con los que se pretende "aristocratizar las nomenclaturas de ciertos oficios y artes", lo que es una forma de "realce expresivo".

\section{ANÁLISIS DE LOS USOS EUFEMÍSTICOS EN EL DISCURSO PÚBLICO Y PERS-} PECTIVAS DE APLICACIÓN

Como resultado de este análisis pretendemos, en primer lugar, explorar posibilidades de aplicación en el ámbito de la lexicografía, o más exactamente, de la lexicografía computacional. El objetivo perseguido consistiría en proporcionar las interpretaciones más aproximadas del sentido en que se usan las expresiones identificadas como tales ejemplos de atenuación, enmascaramiento, ocultación, etc., basándonos en su referencia concreta, es decir, mediante la adecuada contextualización de cada uso concreto. La herramienta que lo posibilita hoy por hoy es el bipertexto (ver especialmente Díaz Noci/Salaverría Aliaga). Desde luego, existen pocas obras lexicográficas relacionadas con el eufemismo, como es el diccionario elaborado por Lechado García, y no se pretende con esta aproximación llegar siquiera a proponer un modelo de entrada léxica para cada uno de estos posibles usos indirectos y fuertemente dependientes del contexto, tanto si están materializados como si no, mediante sustitutos eufemísticos, sino que lo que pretendemos es ampliar las funcionalidades del bipertexto como índice de una forma de definición lexicográfica que resuelva en la medida de lo posible el problema teórico y, sobre todo, metodológico, de la dependencia contextual. En este sentido, la comunicación periodística, sobre todo en relación con las nuevas formas en que se presenta la información en el periodismo digital (Bradshaw), en el marco más general que hemos definido como comunicación pública, supone un dominio de la experiencia que favorecería la utilidad de esta 
aplicación, puesto que en ella el bipertexto ya desempeña todo tipo de funciones comunicativas, no siendo la definición una de las más extendidas, precisamente. En segundo lugar, y como corolario a estos planteamientos, creemos posible el establecimiento de las condiciones necesarias para contribuir a la formulación de propuestas concretas en el marco de una forma de política lingüística que no tiene que ver específicamente con sus fines más habituales, si bien puede considerarse una ampliación de un modelo de desarrollo lingüístico, puesto que estas prácticas discursivas deberían formar parte de códigos deontológicos específicos de cada contexto de comunicación, tales como libros de estilo y guías de buenas prácticas. Esta es una cuestión que hemos abordado recientemente (Fernández Smith 2015) en relación con aquellas otras políticas lingüísticas a las que hemos hecho mención en nuestra introducción.

Así pues, nuestra propuesta de análisis lingüístico del fenómeno tiene su punto de partida teórico en las consideraciones de Casas Gómez (2002) acerca de los niveles del significar. De acuerdo con esto, en el proceso desencadenado por el uso eufemístico, un signo lingüístico materializado en el hablar conlleva un sentido, al menos en parte, diferente del esperado en un contexto concreto cuando, mediante el cambio de su expresión material por la de otro signo contiguo (o por alguna forma de perífrasis o circunloquio), se intenta desplazar en alguna medida el referente en la realidad del signo que inicialmente tendría que haber sido materializado. Ni que decir tiene que dicho desplazamiento del referente nunca se produce porque la realidad extralingüística sigue siendo la misma. Gráficamente:

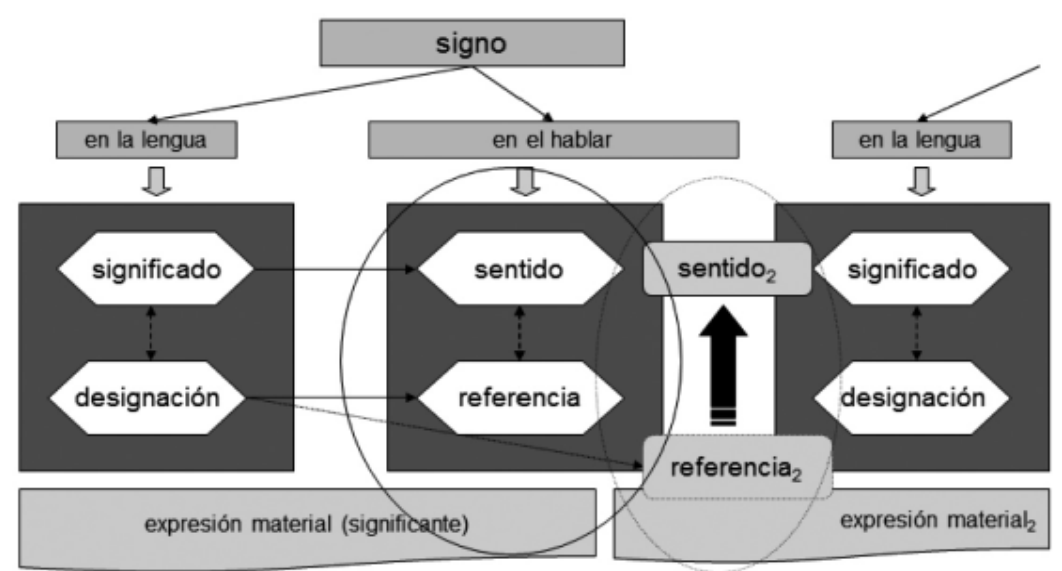

Figura 2 
Los óvalos entrecruzados reflejan la proximidad entre el significar en contexto del signo que deberíamos materializar y el que intentamos que interpreten los receptores, mediante la activación del sentido esperable para otro signo diferente aunque, ya lo hemos dicho, contiguo. Con la flecha más gruesa se pretende representar cómo la intención del emisor es la de ocultar o desplazar, al menos en parte, la realidad extralingüística al modificar el sentido, que teóricamente implica una referencia distinta a la original pero acorde con ese nuevo sentido. Dicho de otro modo, si al signo de la lengua que se materializa con la expresión azafata lo sustituimos en el hablar por la expresión auxiliar de vuelo, también modificamos parcialmente su sentido mediante un supuesto desplazamiento del referente que en realidad nunca se produce. La realidad referida sigue siendo la misma pero la interpretación del signo adquiere otros matices, cierto lustre en este caso (como los eufemismos de megalomanía), pues se le aportan una serie de marcas y connotaciones encaminadas en este caso al ennoblecimiento del término o, quizá más exactamente, incluso a su terminologización. En cualquier caso, lo que se podrá objetar es si la sustitución, cuando realmente se trata de una forma de reemplazo, es verdaderamente un uso eufemistico (para mitigar una realidad desagradable) o disfemístico (para magnificar la importancia de esa misma realidad), o en términos pragmáticos, una estrategia de atenuación o de intensificación. Sea como sea, se trata de enmascarar la realidad y como estrategia pragmática basada en la selección léxica resulta igualmente de interés para los objetivos perseguidos en este trabajo. De hecho, no solo las estrategias de atenuación, sino también las de intensificación, desempeñan funciones similares desde el punto de vista de la manipulación del sentido, toda vez que magnificar la realidad, al igual que mitigarla, es una herramienta válida para desvirtuar el sentido de un texto mediante la distracción de su referente extralingüístico. Un ejemplo muy conocido, dentro del conjunto de los denominados clichés en el lenguaje periodístico, es el uso del adjetivo bistórico. Es curioso cómo los propios profesionales del periodismo son perfectamente conscientes del uso que hacen de estos clichés, pues con motivo del reciente encuentro entre el Papa y el patriarca de la iglesia ortodoxa el 12 de febrero de 2016, hecho que no se había producido antes en la historia, tuvimos la ocasión de oír a un periodista radiofónico de la Cadena COPE que insistía hasta tres veces en el carácter histórico de este encuentro, explicando que este sí era histórico y no en el sentido en que se emplea habitualmente el término. 
El ejemplo ${ }^{7}$ siguiente resulta revelador como muestra de la modificación, o sustitución, en términos lingüístico-textuales, de una expresión material cuyo referente incomoda al emisor sobre la cual construye una estrategia pragmática de atenuación:

\section{Ejemplo 1}

"El ministro del Interior, Alfredo Pérez Rubalcaba, considera que el hallazgo por parte de la Ertzaintza de un bidón con 50 kilos de material explosivo el pasado sábado en el término municipal de Amorebieta (Vizcaya) era «un proyecto de zulo» donde los presuntos terroristas «iban a meter una serie de cosas»". (El Mundo, 29/12/2006)

En este ejemplo, la realidad que se pretende ocultar, 'zulo' (esp. 'agujero'), se convierte en determinación de proyecto. Este último es un concepto que remite a algo que no está realizado, que no tiene existencia real por cuanto puede incluso representar una idea abstracta que todavía está por ejecutar, por tanto, por existir. Más aún, la clara asociación que se produce, por el conocimiento del mundo, entre zulo y arma(s), explosivo(s), detonador(es), etc., ${ }^{8}$ aparece difuminada mediante un mecanismo de cohesión textual muy habitual como es el uso de la proforma lexical cosa (Bernárdez 105-06), que por su indefinición y carencia de contenido léxico puede utilizarse como sustituto de un conjunto enorme de lexemas, contribuyendo así a la indefinición general que el productor del mensaje parece perseguir.

En estos casos, como en tantísimos otros, resultaría de gran utilidad explotar los recursos que proporciona el bipertexto en el periodismo digital actual. En el modelo de Bradshaw, sobre el que hemos discutido en un trabajo anterior (Fernández Smith 2013), el periodista británico explica con absoluta claridad el funcionamiento del proceso de producción de información en el periodismo digital. Este modelo, representado como un diamante en el que se verifican los sucesivos pasos que se siguen en la producción de la información y su recepción por parte del público, se caracteriza por la interactividad con la que los receptores del mensaje pueden incluso llegar a customizar (permítasenos el término, tan en boga hoy en día) su uso de estas fuentes de

7. Emplearemos, como pauta, un formato de fuente en negrita para destacar en cada caso las unidades léxicas o sintagmas objeto de nuestro análisis.

8. Ver más abajo las definiciones del Diccionario de uso del español (DUE) y del Diccionario de español actual (DEA) que hemos recogido. 
información. Es evidente el papel que puede desempeñar en este contexto la herramienta del bipertexto. Al margen de las funciones concretas, muy diversas y no siempre relacionadas con el contenido de la información presentada, que el bipertexto registra en el periodismo actual, es indudable su utilidad, en síntesis y a grandes rasgos, como herramienta de documentación. ${ }^{9}$ Puede verse en la Figura 3 cómo podría facilitarse la interpretación del Ejemplo 1 si la información periodística, mediante el bipertexto, pudiera proporcionar al lector una ficha como la que proponemos, con definiciones en una entrada lexicográfica contextualizada o entrada enciclopédica (por tanto, haciendo uso de otros códigos semióticos), además, por supuesto, de referencias intertextuales a otras informaciones relacionadas con el tema, que es para lo que se utiliza habitualmente esta herramienta:
Zulo $_{1}$ : "Habitáculo, generalmente subterráneo y de reducidas dimensiones, utilizado por un grupo terrorista para ocultar a los secuestrados, almacenar armas, etc.". (DUE)

Zulo $_{2}$ : "Agujero excavado en tierra para esconder algo que se oculta de la policía". (DEA)

\begin{tabular}{ll}
\hline [OTRAS DEFINICIONES] & [OTRAS INFORMACIONES] \\
[IMAGEN REAL] & [IMAGEN ALTERNATIVA] \\
\hline
\end{tabular}

Figura 3

Desde luego, este tipo de procedimientos afectaría directamente a la segunda de las posibilidades de aplicación que proponemos en este trabajo, la que tiene que ver con las otras políticas lingüísticas, por cuanto queda supeditado al juicio de los responsables de la publicación el proporcionar o no esos datos complementarios que podrían llegar a ser muy necesarios para la comprensión cabal del texto. Se trata, obviamente, de una cuestión que afecta a los criterios deontológicos de la profesión, en este caso la periodística, que es una cuestión que creemos que está conectada con esas otras formas de política lingüística que se pueden verificar en otros niveles de organización social, ${ }^{10}$ como puede

9. Hace ya algunos años (Fernández Smith 2007) exponíamos la utilidad que para la lingüística del texto, especialmente en lo relativo al problema de la tipologización, tenían ciertos aspectos teóricos y metodológicos del campo del análisis documental y el análisis de contenido.

10. Precisamente, en relación con esta línea de investigación, también formamos parte de un proyecto, que todavía se encuentra en vías de obtener financiación, sobre "Los discursos inti- 
ser, en el caso que nos ocupa, el de las empresas de comunicación, aunque también el de niveles institucionales y gubernamentales en los que se adoptan medidas de intervención sobre una lengua, pero con finalidades muy diferentes a las que se han establecido habitualmente en la literatura sobre política y planificación lingüísticas.

Así, en el ejemplo siguiente, se muestra cómo la prensa ha reflejado a lo largo de los últimos años el devenir de la discusión en torno a la modificación del Código Penal, según la cual se ha sustituido el término imputado por el de investigado. Como se observa en los siguientes extractos aparecidos en estos años en diferentes medios de comunicación, se trata de un auténtico proceso eufemístico dirigido desde las instancias políticas y judiciales con el que se pretende enmascarar una realidad que, obviamente, no cambia por mucho que cambie la etiqueta empleada para designarla. Es, por ende, un ejemplo de política lingüística muy alejada de los fines para los que se crea y se reelabora el conocido modelo de Haugen (1966; 1983), cuestión esta sobre la que hemos discutido en Fernández Smith (2015).

\section{Ejemplo 2}

El cambio de imputado por encausado es una cuestión de "maquillaje", según los juristas.

Un amplio sector advierte de que la medida es "irrelevante y meramente estética".

Pretende evitar la connotación peyorativa al término imputado.

Aseguran que la modificación tendrá un efecto inicial pero, pasados unos meses, el encausado volverá a colocarse en el punto de mira de la opinión pública. (20 Minutos, 24/05/2013)

Justicia recurre a lingüistas para eliminar la carga negativa del término "imputado".

midatorios (mensajes de odio y amenazas verbales) en las redes sociales en el ámbito de las lenguas del Mediterráneo Occidental”, dirigido por Juan Manuel López Muñoz (Universidad de Cádiz) y Paola Capponi (Universidad Pablo Olavide de Sevilla), y con el que se pretende definir, describir y explicar este tipo de discursos en el actual contexto de crisis económica y socio-cultural en los países del Mediterráneo Occidental, tanto europeos como del norte de África, con el fin, entre otros, de contribuir a propiciar un marco legislativo adecuado que sirva para regular las interacciones en el ciberespacio. 
Justicia busca una solución a la negativa concepción sociológica que rodea el término del "imputado" durante la fase de investigación.

"En Francia se usa la denominación de «testigo cualificado»". (InfoLibre, $01 / 12 / 2014)$

El Gobierno modifica la ley para que los imputados pasen a llamarse "investigados"

El ministro de Justicia, Rafael Catalá, ha manifestado en varias ocasiones que el término imputado tiene en la actualidad "un nivel de contaminación semántico muy alto" [...] Pasará a denominarse encausado según avance el procedimiento. (La Sexta, 13/03/2015)

Es de suponer, además, que en un futuro no demasiado lejano, el nuevo término investigado, creado para evitar las indeseadas asociaciones que los receptores podían establecer entre imputado y, por ejemplo, encausado, adquirirá esas mismas connotaciones a las que se refieren algunos de los extractos anteriores. ${ }^{11}$ Gráficamente:

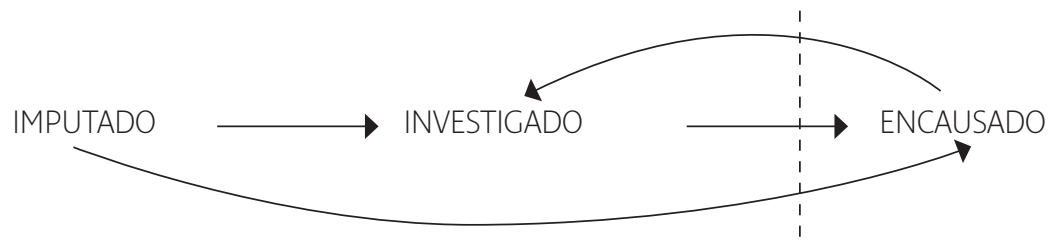

Figura 4

De hecho, buena prueba de que realmente nos encontramos ante un reajuste del contenido lingüístico que sirve de soporte a la realidad extralingüística es que todavía es posible encontrar casos en los que los periodistas están utilizando diferentes fórmulas encaminadas a aclarar cuál es la designación real de investigado:

Además de solicitar que se tenga al concejal como investigado (nueva denominación para imputado), el fiscal pide al juez [...]. (El Mundo, $15 / 03 / 2016)$

11. Ver Casas Gómez (1995) sobre los procesos que explican la inestabilidad del eufemismo. 
Un juzgado de Cádiz ha citado a declarar en calidad de investigado (antes imputado) por un posible delito de falsedad documental [...]. (El Mundo, $08 / 04 / 2016)$

En esta línea, se proponen igualmente sustitutos (¿eufemísticos?) para el denostado término clan en el "Glosario" de la Guía práctica para periodistas que la Fundación Secretariado Gitano editó en 2010. Puede verse la cita del comentario que sobre esta y otras unidades léxicas se hace en dicha Guía en el siguiente ejemplo:

\section{Ejemplo 3}

El léxico utilizado

Hay muchos términos cargados con fuertes connotaciones negativas que se utilizan con frecuencia en las informaciones sobre sucesos y que se acaban asociando inevitable (e injustamente) a la comunidad gitana. Entre otros: clan, reyerta, batalla campal... También es frecuente el uso incorrecto o desaconsejado por la comunidad científica (raza), términos aparentemente neutros que no es correcto asociar a la comunidad gitana si consultamos su significado más preciso (colectivo, xenofobia...) o denominaciones ajenas a lo gitano cuando sí existen las propias (tío/ tía, frente a patriarca o matriarca). (Guía práctica para periodistas 34-35)

Más abajo, se propone:

Evitar el uso de un lenguaje estereotipado o incorrecto (reyerta, raza, clan, patriarca...). (Guía práctica para periodistas 35)

Así, por ejemplo, en el "Glosario" de términos relacionados con el trabajo de la Fundación Secretariado Gitano puede encontrarse la siguiente entrada:

Clan: Algunos medios de comunicación todavía utilizan este término (totalmente inadecuado para referirse a las familias gitanas en general), que puede resultar injurioso por su asociación con actividades delictivas, especialmente con el tráfico de drogas. Para referirse a la familia tradicional gitana (compuesta, además del núcleo familiar por un amplio conjunto de parientes: primos, cuñados, yernos) un término antropológico más adecuado es el de familia extensa o el de grupo familiar. 
En algunos contextos (especialmente cuando se hace referencia a los ascendentes y descendentes familiares) otro término apropiado es linaje). (Guia práctica para periodistas 72)

Puede verse claramente la referencia al carácter antropológico de las denominaciones alternativas que se proponen en esta Guía, que aporta un conjunto de rasgos de contenido cuya proyección en la realidad extralingüística se orienta hacia un dominio, como es el de las relaciones de parentesco y su configuración entre los seres humanos, muy diferente del que es propio de las asociaciones que, según los autores, se establecen en el uso del término clan, el mundo de la delincuencia y el tráfico de drogas. Se trata, por tanto, de desterrar, no ya solo de encubrir o enmascarar, una realidad desagradable que, obviamente, no está necesariamente ligada en todos los casos con los individuos reales que componen el conjunto así designado como clan.

Lo cierto es que en los libros de estilo elaborados por las empresas que editan los diferentes medios de comunicación no se suele, en cambio, entrar en demasiado detalle acerca del uso enmascarador o intensificador del léxico, ni tampoco, ni siquiera en aras de la objetividad que se presume en el estilo informativo, sobre la necesidad de adoptar con la debida cautela el conjunto de términos y expresiones aportadas desde los diferentes grupos políticos o sociales y de las que estos medios se hacen eco tan frecuentemente. Ver los siguientes extractos de los libros de estilo editados por la Agencia EFE y RTVE (Ejemplos 4 y 5 ):

\section{Ejemplo 4}

7.2. Muchas de las extravagancias léxicas que hoy pululan en los medios de información no son achacables a los periodistas, sino a sus fuentes. En efecto: son los políticos, la Administración, los tecnócratas, quienes, con fines muy diversos -que van desde el deseo de singularizarse hasta el de ampararse en la ambigüedad -, ponen en circulación neologismos, muchas veces efímeros: instancias unitarias, autoconvocatorias, etc. [...]

7.3. Se recomienda la variedad de vocabulario. Muchas palabras se repiten en exceso. Así, los actos, los plazos, etc. finalizan siempre (no acaban, terminan o concluyen). Ya no hay cábalas, presunciones, rumores, sospechas, indicios, suposiciones...; todo son especulaciones a la inglesa [...]. (Manual de español urgente 57, de la Agencia EFE) 


\section{Ejemplo 5}

Informar en positivo. El mensaje resulta más claro si se construye en positivo. Siempre que sea posible, deben evitarse las frases negativas. Por idéntico motivo, se prefieren verbos en positivo como, por ejemplo, "rechazar" en lugar de "no admitir" o "prohibir" en lugar de "no autorizar". (Manual de estilo de RTVE [en línea])

Como puede observarse, las recomendaciones y usos léxicos discutidos en estos casos son de naturaleza fundamentalmente estilística (cuando no meramente gramatical), sin que se pueda detectar siquiera un leve rastro de aproximación pragmática a las intenciones comunicativas de los productores de los textos, y mucho menos del análisis crítico del contenido ideológico, y por tanto de su repercusión para el receptor, que justifica en tantas ocasiones las selecciones que estos efectivamente realizan.

Sin embargo, sí es cierto que en otros códigos éticos y deontológicos incluidos en manuales de estilo de El País, El Mundo, etc. se advierte sobre el uso de las generalizaciones, del condicional de rumor y otras prácticas discursivas como formas de presentación sesgada de la información, que deben evitarse. También hay obras, de carácter más bien divulgativo, como la de Pastor, que alertan sobre los usos incorrectos o inadecuados que se han generalizado en el lenguaje periodístico español, pero no hemos encontrado referencias concretas a las cuestiones que aquí hemos presentado y que, en nuestra opinión, sí se corresponderían en puridad con una verdadera deontología profesional que, dada la influencia que los medios de comunicación audiovisual ejercen en la actualidad, sería muy deseable. En este sentido, aunque no hay tampoco en él referencias al uso eufemístico enmascarador, es muy destacable el trabajo colectivo coordinado por Alcoba en 2009, porque aporta una reflexión metateórica sobre el concepto mismo de "libro de estilo", tampoco muy habitual, que nos parece especialmente útil para la justificación de nuestras propias afirmaciones. Los estudios que en él se incluyen abordan muchas de las facetas implicadas en la conformación de los libros de estilo también desde un punto de vista instrumental y práctico, además de cuestiones relacionadas con el papel que desempeñan los medios de comunicación como transmisores de los mensajes de otros, entre los que cabe destacar el lenguaje políticamente correcto y el papel que desempeñan las instituciones y los grupos de poder, entre otros tópicos relevantes que hemos comentado aquí. 


\section{CONCLUSIÓN}

Que "lo que efectivamente se dice es menos de lo que se expresa y se entiende" (Coseriu 1955-56, 308) no es, ciertamente, un axioma cuya validez no haya sido ya demostrada en innumerables ocasiones durante las cinco décadas de investigación lingüística que siguieron a esta afirmación, de manera que no es esta una conclusión nueva en relación con las cuestiones que acabamos de presentar. Con todo, sí es evidente que la importancia de las estrategias comunicativas y pragmáticas relacionadas con el ocultamiento o enmascaramiento del verdadero sentido de lo que se dice vienen a apuntalar aún más y a justificar, por su enorme importancia en el discurso público, esta premisa. De acuerdo con ello, la comunicación pública se desenvuelve, como se ha visto, en contextos comunicativos en los que son especialmente útiles este tipo de estrategias, de ahí que sean tan frecuentes los usos eufemisticos y otras estrategias de atenuación, empleadas para difuminar la realidad que es incómoda, tanto para sus emisores como para, a veces, sus receptores, mediante la manipulación de las unidades lingüísticas efectivamente realizadas, que de alguna forma distraen la interpretación, o bien desplazan esa realidad impertinente, en el contexto en el que se producen.

Resulta especialmente llamativo el hecho de que, como se ha mencionado en numerosas ocasiones, el discurso político y el publicitario son contextos propicios para aquel uso eufemístico que tiene como finalidad el engaño y la manipulación, pues son precisamente tipos de lenguaje en cuyos géneros predomina la secuencia argumentativa, de acuerdo con el modelo tipológico de Adam (1987, 1992, 2011), aun cuando, recordemos, pueden encontrarse estas mismas finalidades en otros marcos genéricos en los que las secuencias dominantes son explicativas o descriptivas, como los contratos de las pólizas de seguros, pero en los que el productor utiliza igualmente estrategias de difuminación del sentido de lo que se manifiesta (Escavy Zamora). Con todo, es razonable considerar que el uso de estos recursos lingüísticos contribuye a la construcción de un entramado argumentativo favorable o desfavorable a una determinada posición ideológica, o estado de cosas con el que se mantiene alguna relación, utilizando estrategias con las que se pretende persuadir a los destinatarios de la veracidad de lo que se dice. Así pues, si bien es claro que, cuando desempeña una función de interdicción el eufemismo es una estrategia comunicativa orientada al receptor, muy relacionada con la cortesía verbal y el decoro, es igualmente cierto que, cuando su empleo sirve a funciones ar- 
gumentativas relacionadas con la prevaricación, el eufemismo como proceso, y, sobre todo, el uso eufemístico como resultado, representan estrategias comunicativas del emisor que busca desactivar determinados contextos que no le son favorables, por razones de muy diversa índole.

Creemos que ha quedado demostrado, de acuerdo con lo que los especialistas citados han señalado ya en muchas ocasiones, que el uso eufemístico, como estrategia de atenuación (o de intensificación) requiere para su mejor comprensión una aproximación pragmática y discursiva, desde una metodología como la que proporciona el Análisis Crítico del Discurso, que nos permita analizar en profundidad el desfase entre lo efectivamente dicho y lo que realmente se expresa o se entiende, sobre todo porque estos procesos y los medios por los que se manifiestan (ya sea mediante la intensificación de unas categorías o la atenuación de otras) actualizan en el contexto pragmático y discursivo un marco cognitivo de representaciones conceptuales cultural, sociológica y/o ideológicamente determinadas.

\section{OBRAS CITADAS}

Adam, Jean-Michel. "Types de séquences textuelles élémentaires". Practiques 56 (1987): 54-79.

Adam, Jean-Michel. Les textes: types et prototypes. París: Nathan, 1992.

Adam, Jean-Michel. La linguistique textuelle. 3. ${ }^{a}$ ed. París: Armand Colin, 2011.

Albelda Marco, Marta. La intensificación como categoría pragmática: revisión y propuesta. Frankfurt am Main: Peter Lang, 2007.

Albelda Marco, Marta. "Atenuación, eufemismos y lenguaje políticamente correcto". Norma y usos correctos en el español actual. Coord. Milagros Aleza. Valencia: Tirant lo Blanch, 2010. 342-74.

Alcaraz Varó, Enrique, y María Antonia Martínez Linares. Diccionario de lingiiística moderna. Barcelona: Ariel, 1997.

Alcoba, Santiago, coord. Lengua, comunicación y libros de estilo. Barcelona: Universidad de Barcelona (2009). 14 de febrero de $2016<$ http://mediamentor.org/es/publications>.

Beaugrande, Robert-Alain de, y Wolfgang Ulrich Dressler. Introduction to Text Linguistics. London: Longman, 1981.

Bernárdez, Enrique. Introducción a la lingüística del texto. Madrid: EspasaCalpe, 1982. 
Bradshaw, Paul. "A model for the 21st century newsroom: pt 1 - the news diamond". Online fournalism Blog (2007). 7 de enero de 2016. <http:// onlinejournalismblog.com>.

Briz Gómez, Antonio. El español coloquial en la conversación. Esbozo de pragmagramática. Barcelona: Ariel, 1998.

Casado Velarde, Manuel. "Algunas estrategias discursivas en el lenguaje periodístico de hoy”. Boletín Hispánico Helvético 12 (2008): 71-89.

Casado Velarde, Manuel. "El poder de las palabras: lenguaje y manipulación". Nueva revista de política, cultura y arte 134 (2011): 162-74.

Casado Velarde, Manuel. "Trust and Suspicion as Principles of Discourse Analysis". Language Use in the Public Sphere. Methodological Perspectives and Empirical Applications. Eds. Inés Olza, Óscar Loureda y Manuel Casado Velarde. Linguistic Insights 170. Bern: Peter Lang, 2014. 53-78.

Casas Gómez, Miguel. La interdicción lingüística. Mecanismos del eufemismo y disfemismo. Cádiz: Universidad de Cádiz, 1986.

Casas Gómez, Miguel. "Sinonimia y eufemismo”. Quaderni di Semantica 16.1 (1995): 17-46.

Casas Gómez, Miguel. Las relaciones léxicas. Beihefte zur Zeitschrift für romanische Philologie. Band 299, Tübingen: Max Niemeyer Verlag, 1999.

Casas Gómez, Miguel. “Tabú de palabra e interdicción conceptual”. Trabajos de lexicografía y fraseología contrastivas. Eds. Antonio Pamies Bertrán y Juan de Dios Luque Durán. Granada: Método Ediciones, 2000. 79-98.

Casas Gómez, Miguel. Los niveles del significar. Cádiz: Universidad de Cádiz, 2002.

Casas Gómez, Miguel. “Towards a new approach to the linguistic definition of euphemism". Language Sciences 31 (2009): 725-39.

Casas Gómez, Miguel. "El realce expresivo como función eufemística: a propósito de la corrección política de ciertos usos lingüísticos”. Political Correctness. Aspectos políticos, sociales, literarios y mediáticos de la censura política. Aspetti politici, sociali, letterari e mediatici della censura linguistica. Aspects politiques, sociaux, littéraires et médiatiques de la censure linguistique. Eds. Ursula Reutner y Elmar Schafroth. Studia Romanica et Linguistica, 38, Frankfurt am Main: Peter Lang, 2012a. 61-79.

Casas Gómez, Miguel. "The Expressive Creativity of Euphemism and Dysphemism". Lexis - Fournal in English Lexicology 7: Euphemism as a wordformation process (2012b): 43-64.

Casas Gómez, Miguel. "De una visión léxica y pragmático-discursiva a una di- 
mensión cognitiva en la caracterización extralingüística y lingüística del eufemismo". Études pragmatico-discursives sur l>euphémisme. Estudios pragmático-discursivos sobre el eufemismo. Eds. Mark Bonhomme, Mariela de la Torre y André Horak. Studien zur romanischen Sprachwissenschaft und interkulturellen Kommunikation, Band 83. Frankfurt am Main/Berlin/ Bern/Bruxelles/New York/Oxford/Wien: Peter Lang, 2012c. 53-72.

Cassany, Daniel. "Explorando los discursos de las organizaciones". Foro Hispánico. Revista Hispánica de Flandes y Holanda 26.1 (2004): 49-60.

Chamizo Domínguez, Pedro José. "La función social y cognitiva del eufemismo y del disfemismo". Panace@ 5.15 (2004): 45-51.

Chamizo Domínguez, Pedro José, y Francisco Sánchez Benedito. "Euphemism and dysphemism: ambiguity and supposition". Language and Discourse 2 (1994): 78-92.

Chamizo Domínguez, Pedro José, y Francisco Sánchez Benedito. Lo que nunca se aprendió en clase. Eufemismos y disfemismos en el lenguaje erótico inglés. Granada: Comares, 2000.

Coseriu, Eugenio. "Determinación y entorno. Dos problemas de una lingüística del hablar". Romanistisches Fährbuch 7 (1955-56): 29-54.

Coseriu, Eugenio. "Las solidaridades léxicas". Principios de semántica estructural. Madrid: Gredos, 1977. 143-61.

Crespo Fernández, Eliecer. El eufemismo y el disfemismo. Procesos de manipulación del tabú en el lenguaje literario inglés. Alicante: Universidad de Alicante, 2007.

Daneš, Frantisek. "Functional sentence perspective and the organization of the text". Papers on functional sentence perspective. Ed. Frantisek Daneš. The Hague/Paris: Mouton, 1974. 106-28.

De la Fuente García, Mario. La argumentación en el discurso periodístico sobre la inmigración. Dosieres Segundas Lenguas e Inmigración, 14 (2008). 1 de noviembre de 2014. <http://www.segundaslenguaseinmigracion.es/>.

Díaz Noci, Javier, y Ramón Salaverría Aliaga. "Hipertexto periodístico: teoría y modelos". Manual de redacción ciberperiodística. Eds. Javier Díaz Noci y Ramón Salaverría Aliaga. Barcelona: Ariel, 2003. 81-139.

Escavy Zamora, Ricardo. "El principio de cooperación y las violaciones antagónicas". VIII fornadas de Lingüística. Dir. M. Casas Gómez y eds. María Jesús Paredes Duarte y Carmen Varo Varo. Cádiz: Universidad de Cádiz, 2004. 47-70.

Fernández Smith, Gérard. "La interdisciplinariedad como marco metodoló- 
gico en la lingüística textual y discursiva". Actas del VI Congreso de Lingüistica General (Santiago de Compostela, del 3 al 7 de mayo de 2004). I. Métodos y Aplicaciones de la Lingüística. Eds. Pablo Cano López, Isabel Fernández López, Miguel González Pereira, Gabriela Prego Vázquez y Montserrat Souto Gómez. Madrid: Arco/Libros, 2007. 113-22.

Fernández Smith, Gérard (2009). "Principio de adecuación y teoría del texto". La linguiistica como reto epistemológico y como acción social. Estudios dedicados al profesor Ángel López García con ocasión de su sexagésimo aniversario. Eds. Monserrat Veyrat Rigat y Enrique Serra Alegre. I. Madrid: Arco/Libros, 2009. 105-14.

Fernández Smith, Gérard. "Contexto pragmático y receptor: la aceptabilidad como norma textual”. Revista de Investigación Linguiística 16 (2013): 61-88. 11 de noviembre de 2016. <http://revistas.um.es/ril/article/ view/208671>.

Fernández Smith, Gérard. "Los límites de la política y planificación lingüísticas". Revista de Linguiistica y Lenguas Aplicadas 10 (2015): 34-43. 7 de enero de 2016. <http://polipapers.upv.es/index.php/rdlyla/article/view/3596>. Fuentes González, Antonio Daniel. "Gente de la sierra, maquis, guerrilleros, bandoleros...: sociolingüística gentilicia para el tiempo abatido". Tonos Digital 28 (2015). 14 de febrero de 2016. <http://www.tonosdigital.com/ ojs/index.php/tonos/article/view/1220/750>.

Fundación Secretariado Gitano. Guía práctica para periodistas. Igualdad de trato, medios de comunicación y comunidad gitana. (2010). 10 de febrero de 2015. <http://www.gitanos.org/upload/54/77/Guia_Practica_Com_FinalCompleto.pdf $>$.

Halliday, Michael Alexander Kirkwood, y Ruqaiya Hasan. Cohesion in English. London: Longman, 1976.

Haugen, Einar. "Linguistics and Language Planning". Sociolinguistics: Proceedings of the UCLA Sociolinguistics Conference, 1964. Ed. William Bright. The Hague: Mouton, 1966. 50-71.

Haugen, Einar. "The Implementation of Corpus Planning: Theory and Practice". Progress in Language Planning. Eds. Juan Cobarrubias y Joshua Fishman. The Hague: Mouton, 1983. 269-90.

Hockett, Charles F. Curso de Lingüística moderna. Buenos Aires: Eudeba, 1971. Laborda Gil, Xabier. Lágrimas de cocodrilo. Análisis del discurso político. Barcelona: UOC, 2012. 
Lechado García, José Manuel. Diccionario de eufemismos y de expresiones eufemisticas del español actual. Madrid: Verbum, 2000.

Lewandowski, Theodor. Diccionario de lingüística. Madrid: Cátedra, 1995.

López García, Ángel. Psicolingüística. Madrid: Síntesis, 1988.

Loureda Lamas, Óscar. "Nuevas perspectivas para el análisis del texto: introducción a una lingüística del texto integral". Revista de Investigación Lingüística 13 (2010): 127-54.

Loureda Lamas, Óscar. "New Perspectives in Text Analysis: Introducing an Integrated Model of Text Linguistics". Language Use in the Public Sphere. Methodological Perspectives and Empirical Applications. Eds. Inés Olza, Óscar Loureda y Manuel Casado Velarde. Linguistic Insights 170. Bern: Peter Lang, 2014. 161-200.

Márquez Guerrero, María. "La paradoja de la atenuación en el discurso político. Su funcionalidad argumentativa en las interpelaciones de parlamentarias y parlamentarios andaluces”. Discurso \& Sociedad 6.1 (2012): $187-215$.

Meyer-Hermann, Reinhard. "Atenuación e intensificación (Análisis pragmático de sus formas y funciones en español)". Anuario de Estudios Filológicos 11 (1988): 275-90.

Moliner, María. Diccionario de uso del español. 3. ${ }^{a}$ ed. 2 vols. Madrid: Gredos, 2007.

Mortara Garavelli, Bice. Manual de retórica. Madrid: Cátedra, 1988.

Pastor, Bárbara. Las perversiones de la lengua. Usos y abusos de las palabras en nuestros días. Barcelona: Planeta, 2001.

Seco, Manuel, dir., Olimpia Andrés y Gabino Ramos. Diccionario del español actual. 2 vols. Madrid: Aguilar, 1999.

Van Dijk, Teun Adrianus. La noticia como discurso. Comprensión, estructura y producción de la información. Traducción de G. Gal, Barcelona: Paidós, 1990.

Van Dijk, Teun Adrianus. Elite discourse and racism. Newbury Park: SAGE, 1993.

Van Dijk, Teun Adrianus. Ideología y discurso. Una introducción multidisciplinaria. Barcelona: Ariel, 2003. 